\title{
ANAP

\section{O CORREDOR TRANSFRONTEIRIÇO: INTERAÇÃO E INTEGRAÇÃO ENTRE O AMAPÁ E A GUIANA FRANCESA}

\author{
José Alberto Tostes ${ }^{1}$ \\ José Francisco Carvalho Ferreira ${ }^{2}$
}

\begin{abstract}
RESUMO
Os territórios transfronteiriços se constituem, em simultâneo, espaços de características multifacetadas, natureza diversa e ambientes complexos e espaços de contato e articulação, de encontro e cooperação. Tratados, por muito tempo, como lugares periféricos, eles assumem-se, hoje, como espaços estratégicos. É neste contexto que este artigo propõe o Corredor Transfronteiriço como uma base reflexiva para compreender a interação e integração do Amapá (Brasil) com a Guiana Francesa (França), dois territórios de fronteira. O objetivo principal deste artigo é definir e apresentar o conceito de Corredor Transfronteiriço, oferendo uma possibilidade de entendimento e fortalecimento das relações sócio-políticas, ambientais e econômicas destes territórios, em todas as suas percepções.
\end{abstract}

Palavras-Chave: Corredor Transfronteiriço; integração; territórios de Fronteira; Amapá; Guiana Francesa.

\section{TRANSBOUNDARY CORRIDOR: INTERACTION AND INTEGRATION BETWEEN AMAPÁ AND FRENCH GUYANA}

\begin{abstract}
Cross-border territories are, simultaneously, multi-faceted, diverse and complex environments spaces and contact and articulation, holding and cooperation spaces. Treated, for a long time, as peripheral places, they take up today as strategic ones. In this context, this article proposes the Transboundary Corridor as a reflexive basis for understanding the interaction and integration of Amapá (Brazil) with French Guyana (France), two border territories. The main purpose of this article is to define and introduce the concept of Transboundary Corridor, offering a possibility of understanding and strengthening the socio-political, environmental and economic relations of these two territories, in all its perceptions.
\end{abstract}

Keywords: Transboundary Corridor; integration; border territories; Amapá; French Guyana

\footnotetext{
${ }^{1}$ Doutor em História e Teoria da Arquitetura. Pós-Doutor em Planejamento Urbano e regional. Docente na UNIFAP. E-mail: tostes.j@hotmail.com

2 Doutor em Geografia e Planeamento Territorial. Pós-doutorando em Desenvolvimento Regional (UNIFAP) e bolsista do PNPD/CAPES. Colaborador do CICS-NOVA da UNL. E-mail: zfcofer@gmail.com.
} 


\title{
EL CORREDOR TRANSFRONTEIRIZO: INTERACCIÓN E INTEGRACIÓN ENTRE O AMAPÁ E A GUYANA FRANCESA
}

\begin{abstract}
RESUMEN
Los Territorios transfronterizos son al mismo tiempo espacios de múltiples facetas, de naturaleza diversa y entornos complejos y espacios de contacto y reunión conjunta y cooperación. Tratada, largo tiempo, como lugares periféricos, son, hoy en día, espacios estratégicos. En este contexto, el presente artículo se propone el Corredor Fronterizo como base reflexiva para la comprensión de la interacción e integración de Amapá (Brasil) con la Guayana Francesa (Francia), dos territorios fronterizos. El propósito principal de este artículo es definir e introducir el concepto de Corredor Transfronterizo, que ofrece una posibilidad de entendimiento y fortalecimiento de las relaciones socio-políticas, ambientales y económicas de estos territorios y su potencial, en todas sus percepciones.
\end{abstract}

Palabras clave: Corredor Transfronterizo; integración; territorios fronterizos; Amapá; Guyana Francesa.

\section{INTRODUÇÃO}

Muito embora localizados no mesmo continente, as relações ente a Guiana Francesa e o Brasil nem sempre foram as melhores. Com mais de 600 $\mathrm{km}$ de fronteira, e depois de quase 100 anos de isolamento e indiferença, só na década de 90 do século XX suas relações começaram a intensificar-se e a materializar-se, com novas perspectivas de interação e união física, que, pela primeira vez, incluiria a zona de fronteira nessa nova dimensão.

Estas relações, sob os mais diversos aspectos, têm vindo a ser estudadas, tanto do lado francês quanto do brasileiro, sobretudo por grupos de pesquisa da Universidade Federal do Amapá (UNIFAP).

Este artigo propõe uma leitura destes dois territórios à luz do que se denominou de Corredor Transfronteiriço, visto aqui como um espaço no qual se materializam as possibilidades de interação e integração do Amapá e da Guiana Francesa e as possibilidades de diversas sinergias que já existem e ou podem existir no futuro próximo, aproximando, de fato, estes dois territórios.

O artigo está disposto da seguinte forma: no primeiro item ter-se-á em conta o Amapá e a Guiana Francesa como territórios periféricos na América do Sul, além de os caracterizar e os considerar em relação ao país de que fazem parte; no segundo item, define-se o Corredor Transfronteriço; no terceiro item, 


\section{ANAP

reflete-se sobre a interação e integração entre estes dois territórios, partindo do contexto dos diálogos institucionais, sem esquecer a interação, entraves e conflitos neste processo de integração, que acaba por condicionar o processo de desenvolvimento regional, terminando com os cenários para uma integração efetiva. $\mathrm{O}$ artigo termina com as considerações finais e com as referências.

\section{Amapá (BR) e Guiana Francesa (FR): territórios periféricos na américa} do sul

A Guiana Francesa (Departamento Ultramarino Francês) e o Estado do Amapá (Brasil) estão situados ao Nordeste da América do Sul, e, junto com o Suriname, a República Cooperativa da Guiana e o Sul da Venezuela, formam o Platô das Guianas. Os dois territórios partilham uma fronteira comum de 665 km, dos quais 360 são constituídos pelo rio Oiapoque (BEAUDOUIN, RIEBLANC E BOYER, 2011).

Fig. 1 - Mapa de Localização do Amapá e Guiana Francesa

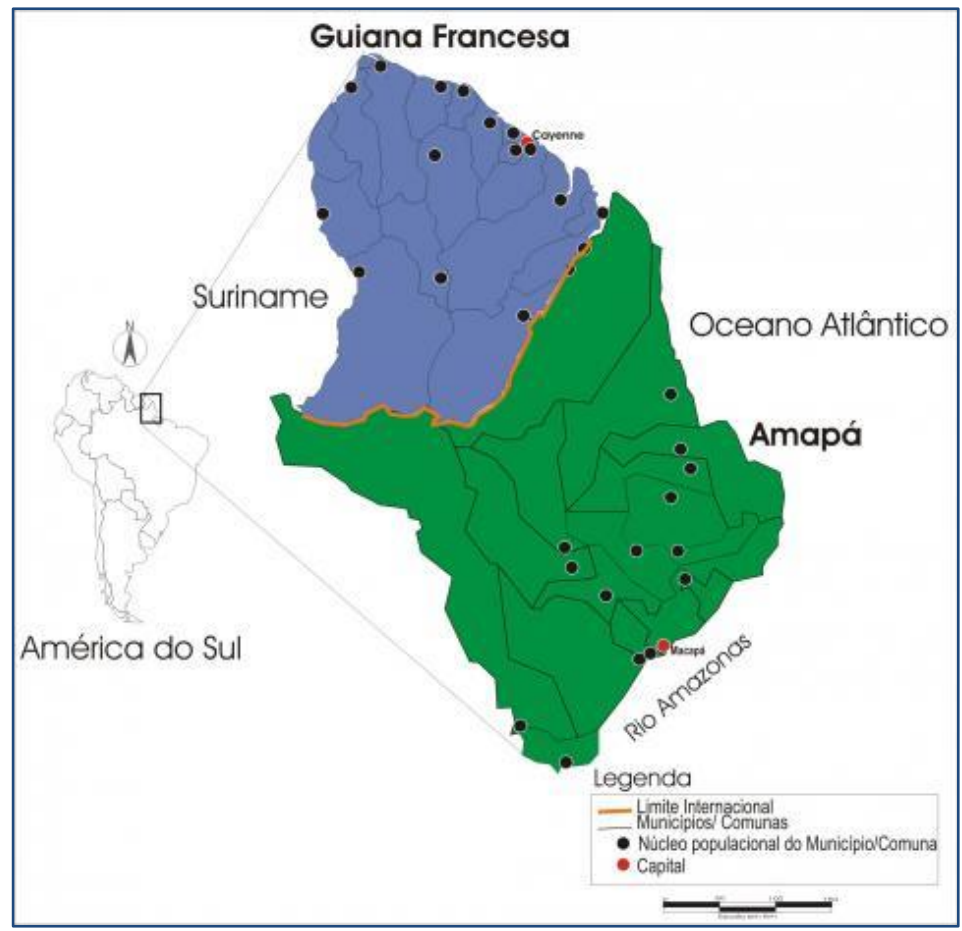

Fonte: Silva \& Rückert, 2009. 


\section{ANAP $\mathfrak{B}_{\text {rasil }}$}

\subsection{Principais características do Amapá e da Guiana Francesa}

O Amapá estende-se sobre uma área de $142815 \mathrm{~km}^{2}$, correspondendo a, $1,7 \%$ da superfície brasileira, sendo considerado um dos menores estados e o menos povoado. Está situado na região Norte do Brasil, fazendo limite, a norte, com a Guiana Francesa, a noroeste, com o Suriname, a oeste e sul, com o Pará, e, a leste, com Oceano Atlântico. Possui 70\% de sua área coberta pela floresta amazônica, sendo conhecido como o estado mais preservado do Brasil, com $72 \%$ de seu território dentro de áreas de preservação ambiental (PORTO, 2010; SUPERTI \& SILVA, 2015).

O estado do Amapá encontra-se divido em 16 municípios e, de acordo com o IBGE (2014), tem uma população estimada de 750.912 habitantes, que representa $0,37 \%$ da população do país. É importante destacar que deste total cerca de $60 \%$ se concentra na capital, Macapá. Possui em sua cultura a diversidade encontrada na região Norte e Nordeste por meio da crescente imigração vinda de tais regiões, havendo também influência cultural por parte da Guiana Francesa (TOSTES, 2011).

O Amapá possui baixa relevância em termos econômicos no conjunto nacional. O setor industrial, extrativista e agrícola do estado é pouco explorado, sendo que a base das atividades econômicas está dependente dos setores comercial e público. De acordo com Beaudouin, Rieblanc e Boyer (2012) as atividades industriais representam apenas $4,2 \%$ do PIB do estado, destes $1,6 \%$ são das indústrias extrativistas e $2,6 \%$ das indústrias de transformação.

No estado existe um grande potencial hídrico, dispondo de variadas possibilidades na integração econômica por meio deste. No setor energético temos, por exemplo, a construção de três novas hidrelétricas: Ferreira Gomes, Santo Antônio do Jari e Cachoeira Caldeirão (e ampliação da Hidrelétrica Coaracy Nunes), que contribuirão para o desligamento de termoelétricas e exportação de energia para outros estados brasileiros e países vizinhos, onde se enquadra a Guiana Francesa. 


\section{ANAP $B_{\text {rasil }}$}

ISSN 1904-3240

V. 8, n. 11

\section{REVISTA}

A Guiana Francesa, com nome oficial Departamento Francês do Ultramar, tem uma superfície de $83534 \mathrm{~km}^{2}$, cerca de $16 \%$ do território francês, tornando-a a maior região francesa. Está situada na América do Sul, sendo limitada, a norte, pelo Oceano Atlântico, a leste e sul, pelo estado do Amapá, a oeste, pelo Suriname. O único limite entre a Guiana e o Brasil é o rio Oiapoque. O Departamento faz parte da Amazônia Legal, possuindo cerca de $95 \%$ do solo coberto por floresta. É composto por 22 cidades e vilas, apresentando uma população estimada, em 2014, de 250.377 habitantes (INSEE, 2014), o que representa $0,38 \%$ da população da França, sendo que de $25 \%$ a $30 \%$ se concentra na capital, Caiena.

A Guiana Francesa apresenta baixa representatividade econômica para a França. Tem na distribuição do valor agregado, a predominância do setor secundário, estendido às atividades extrativistas. De acordo com Beaudouin, Rieblanc e Boyer (2011), o setor industrial representa $11,4 \%$ do seu PIB, revelando que há maiores investimentos neste setor que no estado do Amapá. Nas questões de natureza energética apresenta diversas disparidades e fragilidades.

À semelhança do Amapá, possui portos em localizações estratégicas, embora estes apresentem um calado menor. Esta diferença impede a recepção de grandes navios por parte da Guiana Francesa, afetando, principalmente, a população da capital, Caiena, pois o processo de importação dos produtos é realizado em pequenos navios (LIMA, 2013).

\subsection{O Amapá para o Brasil e a Guiana Francesa para a França}

O estado do Amapá, no contexto nacional, é visto como uma região periférica (PORTO, 2010, 2013; SILVA e TRINDADE JR, 2013). Segundo Beaudouin, Rieblanc e Boyer (2011), este é isolado em relação ao restante do país, dada a presença da barreira natural amazônica (Bacia e floresta), que 


\section{ANAP Brasil $_{\text {ra }}$ \\ ISSN 1904-3240 \\ V. 8, n. 11}

\section{REVISTA}

impede a sua interligação rodoviária, diminuindo sua área de influência (GRANGER, 2008; SANTOS, 2012).

A Guiana Francesa é considerada uma Região Ultraperiférica (RUP). Segundo Santos (2013), esses territórios são caracterizados por grande afastamento geográfico do continente europeu. Por estarem em regiões distantes das grandes correntes de trocas comerciais, estas têm uma enorme dificuldade em tirar proveito do mercado interno da UE e de manter relações comerciais com países vizinhos que pertencem a áreas econômicas diferentes.

\section{O CORREDOR TRANSFRONTEIRIÇO}

Os territórios transfronteiriços, mais do que uma simples divisão física de territórios soberanos, são espaços de características multifacetadas e de natureza diversa, associados a ambientes complexos (PORTO \& SILVA, 2010; WESLEY, 2012). Se em tempos eram marcados por nacionalismos e militarismos, diretamente ligados ao princípio da soberania territorial, essa concepção foi dando lugar a espaços entendidos de contato e articulação, encontro e cooperação, transição, interface, sinergia e ou comutação (PORTO \& NASCIMENTO, 2010; WESLEY, 2012).

A complexidade destes territórios relaciona-se a baixas densidades (populacionais, econômicas, sociais, de infraestrutura, culturais), apresentandose fragmentados e periféricos, com desvantagens naturais, limitações de infraestruturas de transporte, falta de coerência na gestão dos ecossistemas transfronteiriços e mesmo exploração ilegal de trabalhadores (SILVA \& RÜCKERT, 2009).

Identificam-se, igualmente, uma alta sensibilidade geopolítica, contrabando de ouro e diamantes, biopirataria, grilagem de terras e desmatamento ilegal, narcotráfico, lavagem de dinheiro, vulnerabilidade da floresta, pobreza da população e localização próxima dos principais produtores de coca (NASCIMENTO \& COUTO, 2010). 


\section{ANAP Brasil $_{\text {ra }}$ \\ ISSN 1904-3240 \\ V. 8, n. 11}

\section{REVISTA}

É neste contexto que se tem percebido uma dinâmica interessante e que tem a ver com o fato de o Amapá ser tratado como periférico pelas elites locais regionais e pelos órgãos de planejamento federal, constituindo, ao mesmo tempo, espaço estratégico por ser área de segurança nacional e geopoliticamente estratégica para a soberania nacional (PORTO, 2010; SUPERTI \& SILVA, 2015). O oportunidades se abrem por uma localização privilegiada, sejam elas pela abertura ao Atlântico (influência direta do Porto de Santana - e daí ao mundo inteiro), seja pela relação privilegiada com a Europa e o Caribe, possibilitando, por exemplo, uma rota turística internacional e comercial (SILVA \& TRINDADE JR, 2013).

Superti \& Silva (2015, p. 131), referindo-se à Amazônia como um todo (e suas áreas de fronteira), evidenciam que, além das questões de defesa nacional, esta "emerge com um espaço estratégico para a efetivação da integração de redes logísticas e técnicas". Os autores apontam as fronteiras internacionais como peças-chave no processo de integração física, assim como a abundância de recursos, objeto de interesse do grande capital e de redes internacionais.

O Amapá conta 8 dos seus 16 municípios na faixa de fronteira: Oiapoque, Laranjal do Jari, Amapá, Calçoene, Ferreira Gomes, Pedra Branca do Amapari, Serra do Navio e Pracuúba (TOSTES, 2011). Dentre estes, somente o Oiapoque possui sede na linha de fronteira, constituindo cidade gêmea com a cidade de Saint-Georges. Segundo Silva e Trindade Jr. (2013), estas apresentam grande potencial de integração econômica, cultural e ambiental, mas também constituem amostras condensadas dos problemas característicos da fronteira internacional.

É neste contexto de clara complexidade que o pesquisador da Universidade Federal do Amapá, José Alberto Tostes, começou a refletir no que denominou de Corredor Transfronteiriço (CT), com o intuito de estudar e entender as relações entre o Amapá e a Guiana Francesa.

O Corredor Transfronteiriço é, assim, o locus onde se intersecionam o conjunto de condições infraestruturais, físicas, sociais, econômicas, diplomáticas, ambientais e culturais que visam estabelecer relações e o seu 


\section{ANAP

entendimento entre o Amapá e a Guiana Francesa, em sua percepção local, regional, internacional e global. Compreende um vasto conjunto de infraestruturas e de interligações que vão de Santana a Caiena, passando pela ligação da BR 156 à transguianense, sem olvidar as questões ambientais (Figura 3), que permeiam tais elementos, e o conjunto de pequenas cidades posicionadas neste corredor (PELAES, TOSTES \& JUALLINELI, 2013) (Figura 2).

Figura 2 - Eixo central do Corredor Transfronteiriço

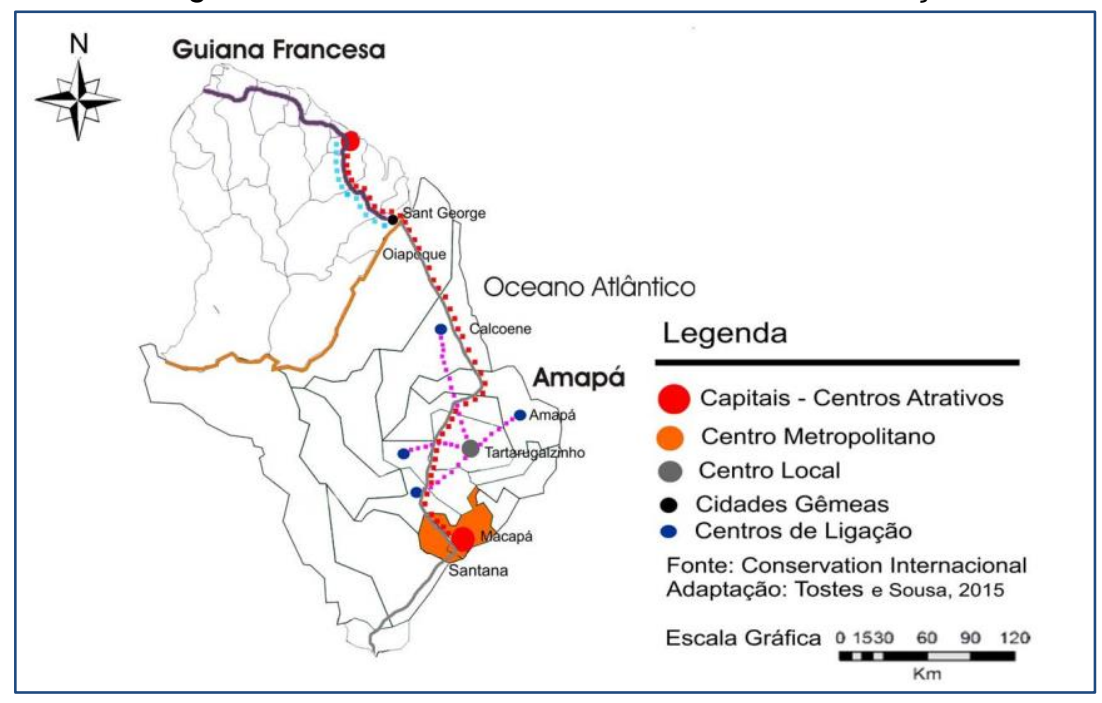

À exceção de Santana e Oiapoque, e Caiena, as cidades do CT têm menos de 20.000 habitantes, tratando-se, pois, de pequenas cidades. Superti \& Silva $(2015$, p. 141$)$ assinalam que elas "...representam o locus por excelência das múltiplas articulações comunitárias, das sedes das empresas voltadas à exploração dos recursos naturais, das forças de atração dos fluxos migratórios.". Do mesmo modo, "... são também o lugar de concentração de considerável parcela da população e dos mais agudos problemas sociais e ambientais.", razões pelas quais elas são de crucial importância para o CT.

Santana, com um porto de grande calado (SUPERTI \& SILVA, 2015), é de crucial importância para o CT, por ser uma das principais portas de entrada e saída de mercadorias e divisas do Amapá e da região Amazônica (LIMA, 


\section{ANAP Brasil $_{\text {ra }}$ \\ ISSN 1904-3240 \\ V. 8, n. 11}

2013), e porta de entrada de muitos migrantes que chegam ao Amapá em busca de melhores condições de vida, inclusive, com a pretensão de chegar à Guiana Francesa (GRANGER, 2008).

Sendo o calado do porto de Caiena menor, o de Santana constitui a possibilidade de as mercadorias chegarem em navios maiores, diminuindo 0 custo do transporte, importante aliado para a dinâmica econômica de ambos os territórios, se integrados (LIMA, 2013; SUPERTI \& SILVA, 2015). Granger (2008), referindo-se à cooperação econômica entre a Guiana Francesa e a restante América do Sul, observa que esta não é marcada por grandes êxitos, já que poucas mercadorias atravessam legalmente a fronteira.

Macapá, capital do estado do Amapá, com população estimada de aproximadamente 450 mil habitantes (IBGE, 2014), assume-se com centro subregional, com capacidade de polarizar e influenciar um número significativo de cidades menores e articular relações de toda ordem. Como nos refere Santos (2012, p. 220), ela "...funciona como principal portão de entrada da Amazônia Setentrional Amapaense e para o acesso internacional às Guianas, em especial, para a cidade de Caiena, na Guiana Francesa".

A BR 156 e a transguianense são o eixo a partir do qual várias pequenas cidades se constituem e se interligam (Figura 2). Quando completamente asfaltada, constituirá a espinha dorsal do corredor transfronteiriço, na parte do território brasileiro. Na parte do território guianense, essa função é da transguianense, antevendo-se, assim, a possibilidade de fomentar articulações de redes técnicas entre o Brasil, a Guiana Francesa e os outros países do Platô das Guianas (SILVA, 2009).

Neste sentido, a ponte binacional constitui o garante do fortalecimento destas relações, ao ligar o Brasil ao departamento ultramarino francês. $O$ fato de não estar ainda operacional tem levantado dúvidas, que geram, até ao momento, incertezas e expectativas goradas. Num futuro próximo constituirá um dos suportes para potenciar sinergias entre os dois países e promover as almejadas relações de comércio e intercâmbio cultural (SILVA, 2009). 


\section{ANAP

Outro elemento importante neste corredor é a forte presença de população indígena de um lado e do outro da fronteira e a questão ambiental. A este respeito, Superti \& Silva (2015) chamam à atenção para o fato de $10 \%$ do território amapaense ser protegido por demarcação de Terras Indígenas e 62\% de áreas de proteção ambiental estadual, federal e privada.

No lado da Guiana Francesa contam-se o Parque Natural Amazonien de Guyane, de proteção integral (2007), e terras indígenas, ambos totalizando mais de 3.400.000 ha (Santos, 2012). Segundo Fonseca (2008), por essa proximidade entre as áreas de preservação, forma-se uma das maiores zonas terrestres protegidas do mundo (Figura 3 ).

Figura 3 - Mapa das Áreas Protegidas e Territórios Indígenas do Amapá e da Guiana Francesa

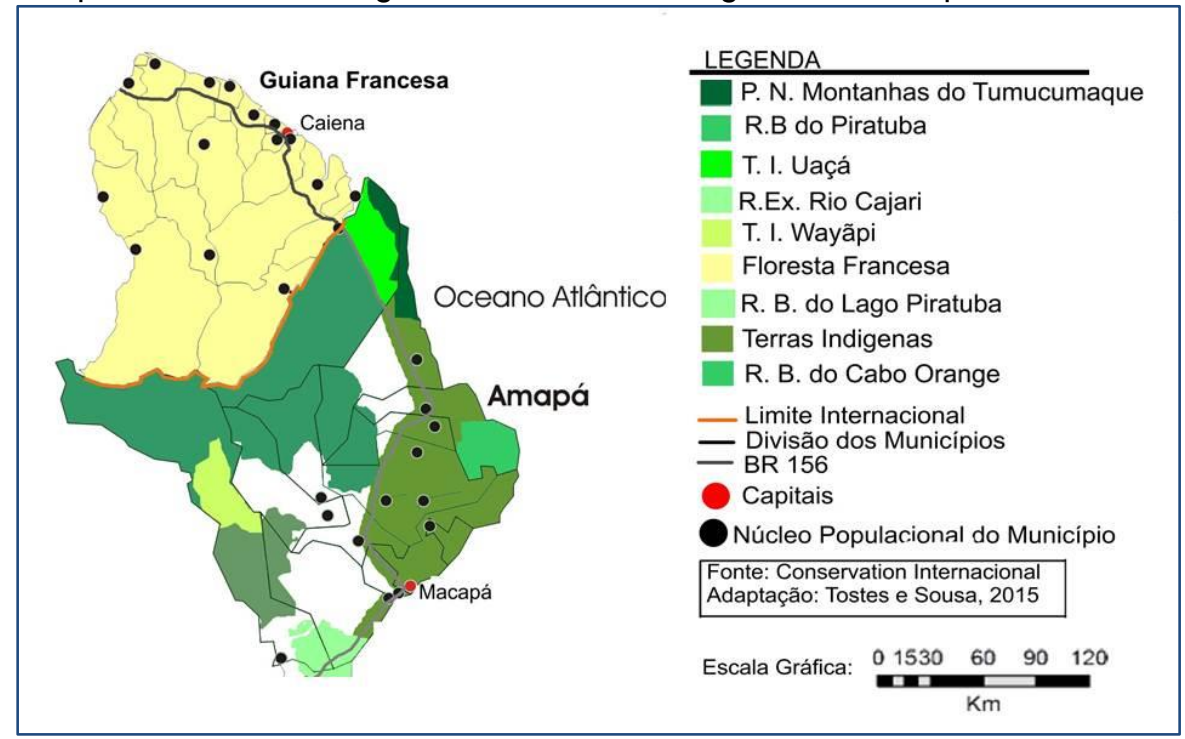

Segundo Silva \& Trindade Jr. (2013), a existência de vários grupos indígenas e a questão ambiental favoreceu que o governo federal, no caso brasileiro, definisse áreas de restrições de uso dos recursos naturais e promovesse um processo de demarcação e regularização das terras indígenas, que envolvem boa parte da área de fronteira do Amapá.

Um outro importante elemento assinalado por Superti \& Silva (2015) é o fato de o Amapá estar vinculado com as redes internacionais e com o grande 


\section{ANAP $B_{\text {rasil }}$ \\ ISSN 1904-3240 \\ V. 8, n. 11}

capital, mesmo que isso não elimine sua condição periférica (ver SILVA, 2009). O objetivo é torná-lo competitivo no cenário mundial, como fornecedor de commodities, mediante a criação de um corredor de exportação (GRANGER, 2008; SUPERTI \& SILVA, 2015).

\section{INTERAÇÃO E INTEGRAÇÃO ENTRE O AMAPÁ E GUIANA FRANCESA}

\subsection{O contexto de reconstrução dos diálogos institucionais}

A retomada do diálogo entre o Amapá e a Guiana Francesa, a partir da década de 1990, deixou para trás décadas de isolamento (GRANGER, 2008). Esta foi motivada, principalmente, pelas vulnerabilidades na região de fronteira e passou inicialmente pela viabilização de uma cooperação transfronteiriça no campo político, econômico, cultural, técnico e científico (NASCIMENTO, 2014).

Um dos maiores problemas entre o Amapá e a Guiana Francesa tem sido conter o número de brasileiros que chegam à fronteira. Contudo, não existe na Guiana Francesa qualquer programa oficial para atração de brasileiros para aquele território. É importante salientar que, ao longo de mais de quarenta anos, a condição migratória na fronteira obedeceu a necessidades sazonais do território guianense-francês, que se manifestava de acordo com os estágios de desenvolvimento (FONSECA, 2008).

Segundo Arouck (2000), o trânsito de brasileiros para a Guiana francesa tem como causa dois fenômenos sociais. Do lado do país de origem (Brasil), as más condições macroeconômicas, que se apresentavam a partir dos anos oitenta. Do lado francês, a ampliação do projeto espacial europeu, marco econômico para o desenvolvimento de serviços, a base de Kourou (menos de $100 \mathrm{~km}$ de Caiena) e a Company Town, nos arredores do complexo.

Para Police (2009), há um ressentimento que orienta e impregna olhares e discursos. Estes discursos alimentam um sentimento de injustiça, de provocação sobre o que representa o Eldorado Francês. Apesar dos riscos que 


\section{ANAP $B_{\text {rasil }}$ \\ ISSN 1904-3240 \\ V. 8, n. 11}

\section{REVISTA}

correm os imigrantes brasileiros, quando calculam ganhos e perdas, se apegam às vantagens, mesmo mantendo-se na clandestinidade.

\subsection{Interação, entraves e conflitos no processo de integração}

Fonseca (2008) destaca que o período de 1995 a 2002 foi o mais frutífero na consecução das políticas regionais de cooperação entre Brasil/Amapá e França/Guiana Francesa. Partiu do Governo do Amapá, de João Alberto Capiberibe, o início das interlocuções visando o desenvolvimento da cooperação transfronteiriça.

Fazendo referência à "1르 Reunião Franco-Brasileira Sobre Cooperação Transfronteiriça: propostas para a cooperação Amapá-Guiana Francesa", Fonseca (2008), assinala que, no discurso introdutório desta reunião, o Amapá foi considerado compatível com a formação de um polo econômico regional guianense, pela sua dimensão econômica e populacional, dado ter mais de 600 $\mathrm{km}$ de fronteira terrestre com a Guiana Francesa e que separam a MERCOSUL da Europa.

Com a assinatura do Acordo-Quadro de cooperação entre BRASILFRANÇA (1996), bem como o memorando de entendimento na área de turismo entre os países, criou-se um ambiente diplomático favorável à intensificação da cooperação transfronteiriça (NASCIMENTO, 2014). Entretanto, a perspectiva de integração regional requeria um considerável esforço por parte do Estado e da União na construção de infraestruturas, notadamente de transportes e energia (SUPERTI \& SILVA, 2015). Entre os pontos mais importantes, Fonseca (2008) destaca a interligação do estado do Amapá e a Guiana Francesa, rompendo obstáculos de infraestrutura rodoviária.

A Ponte Binacional, antigo projeto adormecido por um período longo, foi retomada pelos acordos bilaterais. Esta é valorizada e institucionalizada através da vontade de cooperação de protagonistas regionais do Amapá e da Guiana, instrumentalizada também pela geopolítica estratégica e econômica, 


\section{ANAP $B_{\text {rasil }}$ \\ ISSN 1904-3240 \\ V. 8, n. 11}

gerando novas perspectivas de interação e união física, que incluiria, pela primeira vez a zona de fronteira (NASCIMENTO, 2014).

De acordo com Silva \& Tostes (2011), o elo entre a ponte binacional e a estruturação da Rodovia BR 156 implica em uma série de configurações no espaço geográfico do norte da América do Sul, a partir do Amapá. Embora na primeira década do novo milênio várias ações tenham sido desenvolvidas entre Brasil/França e Amapá e Guiana Francesa, que culminaram no avanço de frentes institucionais de cooperação, houve, igualmente, um conjunto de entraves da mesma ordem de grandeza, que dificultaram maiores avanços.

Os garimpos ilegais e o trânsito de migrantes em direção ao território guianense, em vários momentos, geraram desconfortos para ambos os lados (SILVA \& RÜCKERT, 2009). Para Tostes (2009), há distorções entre o Brasil e a França. A França defende o direito de lutar contra a clandestinidade e contra os danos causados pelos garimpos clandestinos e o Brasil-Amapá denuncia maus tratos praticados pela polícia guianense.

\subsection{Novos cenários para a realização da integração efetiva entre o Amapá e a Guiana}

Para Superti \& Silva (2015), o cenário amapaense tem de ser considerado na confluência de alguns aspectos. O primeiro deles, uma nova dinâmica econômica, que incide no acirramento do mercado das terras e na abertura de áreas com cultivos agrícolas para exportação. O Segundo, um novo ritmo das relações comerciais com os mercados internacionais com densidade para minérios. $O$ terceiro, os produtos do extrativismo vegetal, onde o Amapá tem tradição histórica de exportação. Do mesmo modo, assinalam que novas expectativas se formam com a possibilidade de exploração de petróleo na costa do Amapá.

Segundo Superti \& Silva (2015), a efetivação da Ponte Binacional abre possibilidades concretas para o desenvolvimento econômico e social do 


\section{ANAP $B_{\text {rasil }}$}

ISSN 1904-3240

V. 8, n. 11

município de Oiapoque, principalmente do potencial turístico. Por outro lado, as políticas públicas em área transfronteiriça não vislumbram a inserção de mecanismos de desenvolvimento urbano em escala local. Estas só serão viáveis através de políticas estruturais socioeconômicas no contexto regional e do lugar, sem as quais a cidade de Oiapoque e Saint-Georges serão apenas rotas de passagem.

As distintas conexões com a América do Sul deverão ser fortalecidas através de interesses conjuntos, no que tange à circulação de mercadorias, reflexos de diretos fatores econômicos. A junção de esforços e interesses poderá ocorrer a cargo da iniciativa de Integração da Infraestrutura Regional Sul-Americana (IIRSA), em sintonia com os planos governamentais como 0 Programa de Aceleração do Crescimento (PAC) no Brasil, e, quem sabe, com outros acordos integrados com a França/Guiana Francesa.

No contexto geopolítico brasileiro estão localizadas no Amapá as chamados obras importantes, embora a constituição de redes de circulação no estado seja ainda muito precária. Estratégias de desenvolvimento, ligadas a infraestruturas (rodovias, ferrovias, portos, hidrelétricas), cobrem poucas faixas do território estadual que sempre estiveram vinculadas a grandes interesses.

A Ponte Binacional e a BR 156 são importantes não apenas para o estado do Amapá, mas para consolidar estruturas de redes técnicas e conexões com o Platô das Guianas, possibilitando transformações sobre ambos os territórios. A ponte binacional não é somente o nódulo de uma rede técnica regional, mas implica uma mudança de cenário com conotações de natureza cultural, social, ambiental e principalmente econômica, se consideradas as possibilidades de cooperações com países do Platô das Guianas.

Silva \& Tostes (2011) destacam que irá ocorrer a instalação de um sistema de engenharia (portos; aeroportos; rodovias; sistemas de telecomunicação entre outros), facilitando a integração regional a partir da concepção de fronteira como um sistema aberto, lugar de encontro e 


\section{ANAP Brasil $_{\text {ra }}$ \\ ISSN 1904-3240 \\ V. 8, n. 11}

\section{REVISTA}

cooperação. Serão concretizados os anseios de franceses e brasileiros na possibilidade de aproximação com mais acordos comerciais, transferências tecnológicas e gestão compartilhada de conhecimentos e uso da biodiversidade tropical.

Será efetivada a conexão rodoviária entre as capitais Macapá e Caiena, facilitando a circulação de mercadorias e capitais entre essa região transfronteiriça e mercados mais alargados. Assume, também, particular relevância a configuração estruturada da rodovia transguianense, via de circulação que compreende uma rede técnica que vai de Macapá até Boa Vista, passando por faixas do território da Guiana Francesa, Suriname e República Cooperativa da Guiana.

\section{CONSIDERAÇÕES FINAIS}

Muitas e de níveis diferentes são as interações entre o Amapá e a Guiana Francesa e enorme o esforço de integração entre estes territórios de fronteira. Depois de 15 anos passados da reunião que criou a IIRSA, tem havido uma falta de interesse para que as discussões sobre a sua existência e andamento se tornem públicos, sendo mais fácil executá-los em reuniões fechadas e com poucos integrantes, como tem acontecido. As políticas locais, tanto do Amapá, quanto da Guiana Francesa, pouco levam em conta as estratégias delineadas, impossibilitando, até ao momento, uma real integração.

A construção da Ponte binacional sobre o rio Oiapoque é um avanço significativo do diálogo, quando se reestabeleceu um amplo processo diplomático entre os países. Também é fato que, em décadas, ocorreram descasos do Amapá em relação à integração Sul- Americana. As implicações estão no descompasso e no fluxo de se estabelecer um comércio efetivo com o Platô das Guianas. O atraso nas obras de conclusão da BR 156 no Amapá evidencia a fragmentação de tais projetos considerados estratégicos para 0 país e para o desenvolvimento regional local. 


\section{ANAP

Para existir uma cooperação efetiva é necessário ir além do contexto atual das redes de conexão e questões geopolíticas. Faz-se mister trazer para a discussão temas relacionados à cultura local e ao desenvolvimento urbano em escala local. Defende-se a cooperação equitativa para integrar os olhares e as representações recíprocas. Portanto, as redes estruturantes que se visionam no Corredor Transfronteiriço permitem idealizar uma nova configuração econômica, social, cultural e ambiental entre ambas as regiões.

\section{REFERÊNCIAS}

AROUCK, Ronaldo. "Brasileiros na Guiana Francesa. Novas Migrações internacionais ou exportação de tensões sociais na Amazônia?”. Lusotopie, p. 67-78, Maio de 2000.

BEAUDOUIN, Morgane; RIEUBLANC, Eve; BOYER, Sandie (Coord.). Guiana Francesa Amapá: Melhor estruturar os territórios para intensificar os intercâmbios. Tradução $R$. Laurent. Sage: Guyama280, 2011.

FONSECA, Jean S. Dinâmica territorial da fronteia Amapá: Guiana Francesa sob a influência da integração: 1995 a 2007. 2008. 78f. Dissertação (Mestrado em Geografia) Programa de Pós-graduação em Geografia, Universidade Federal do Pará, Belém.

GRANGER, Stéphane. "Guiana Francesa, um território europeu e caribenho no caminho da sul- americanização?" Revista Eletrônica Ateliê Geográfico, Vol. 2, № 2, p. 156-168, Goiânia, ago/2008.

HAUTEFEUILLE, Madeleine Boudoux. "A fronteira num jogo de poder multiescalar: a França, a Guiana e a ponte sobre o Oiapoque". Revista PRACS, № 2, p. 1-17, dezembro de 2009.

LIMA, J. F. A. Cidades de Santana (AP) e Caiena (GF): um estudo comparativo sobre a concepção de planejamento urbano - 2000-2011. 2013. Trabalho de Conclusão de Curso do Curso de Arquitetura e Urbanismo - Universidade Federal do Amapá, Macapá.

NASCIMENTO, Durbens M.; COUTO, Aiala C. O. "Estado fronteira e redes na Amazônia: uma contribuição ao debate.". In: PORTO, Jadson L. R.; NASCIMENTO, Durbens M. (Orgs.). Interações Fronteiriças no Platô das Guianas: Novas construções, novas Territorialidades. Rio de Janeiro: Publit, 2010. P. 17-44.

PELAES, Fátima; TOSTES, José A.; JUALLINELI, A. R. "Amapá e Guiana Francesa: Novos usos e transformações na faixa de fronteira". In: ENCONTRO NACIONAL DA ASSOCIAÇÃO NACIONAL DE PÓS-GRADUAÇÃO EM PLANEJAMENTO URBANO REGIONAL, 15을 edição, 2013, Recife. Anais do xv encontro da ANPUR. Rio de Janeiro: ANPUR, 2013. v. 1. p. 160-160.

POLICE, Gerard. Eudorado: Le discours brésilien sur La Guyane française. Ibis Rouge Éditions. França, 2009. 
PORTO, Jadson L. R. "Expectativas da fronteira da Amazônia Setentrional: a busca pela interação do Platô das Guianas". In: PORTO, Jadson L. R.; NASCIMENTO, Durbens M. (Orgs.). Dinâmicas periférico-estratégicas da fronteira da Amazônia Setentrional: das políticas públicas e redes institucionais à integração espacial. Rio de Janeiro: Publit, 2013. p. 165-183.

"A Condição Periférico-Estratégica da Amazônia Setentrional: A inserção do Amapá no Platô das Guianas". In: PORTO, Jadson L. R.; NASCIMENTO, Durbens M. (Orgs.). Interações Fronteiriças no Platô das Guianas: Novas construções, novas territorialidades. 1를 Edção. Rio de Janeiro: Publit, 2010. p. 139-160.

PORTO, Jadson L. R.; NASCIMENTO, Durbens Martins (Orgs.). Interações fronteiriças no Platô das Guianas: Novas construções, novas territorialidades. Rio de Janeiro: Publit Soluções Editoriais, 2010, vol. 1.

SANTOS, Emmanuel R. C. Amazônia Setentrional Amapaense: do "mundo" das águas às florestas protegidas. 2012. Tese (Doutorado em Geografia) - Programa de Pós-Graduação em Geografia, Universidade Estadual Paulista, São Paulo.

SANTOS, Paula G. S. A (ultra) periferia do Platô das Guianas: novos planejamentos para novos usos da fronteira Amapá-Guiana francesa (1992-2012). 2013. Dissertação (Mestrado em Desenvolvimento Regional) - Universidade Federal do Amapá, Macapá.

SILVA, Ana R. F.; TRINDADE JR, Saint-Clair C. "Pensando a diferenciação socioespacial na Amazônia: a sub-região fronteiriça internacional dos estados do Pará e Amapá". In: PORTO, Jadson L. R.; NASCIMENTO, Durbens M. (Orgs.). Dinâmicas periférico-estratégicas da fronteira da Amazônia Setentrional: das políticas públicas e redes institucionais à integração espacial. Rio de Janeiro: Publit, 2013. P. 31-65.

SILVA, Gutemberg V. "A integração física sul-americana. Redes técnicas, território e a escala de ação nos Planalto das Guianas". In: ALMEIDA, Alfredo W. B.; CARVALHO, Guilherme (Orgs.). O Plano IIRSA a visão da sociedade civil Pan-amazônica. Belém: Act!onaid, 2009. P. 213-248.

SILVA, Gutemberg V.; RÜCKERT, Aldomar A. "A fronteira Brasil-França. Mudança de usos político-territoriais na fronteira entre Amapá (BR) e Guiana Francesa (FR)". Revista Confins, № 7, p. 1-21, 2009.

SILVA, Gutemberg V.; TOSTES, José A. "Objetos técnicos que re-configuram uma realidade periférica: notas sobre a organização do espaço amapaense vista pela ótica das redes técnicas.". In: ENCONTRO NACIONAL DA ANPUR, XIV Edição, Rio de Janeiro, 2011.

SUPERTI, Eliane; SILVA, Gutemberg V. "Integração Internacional e Políticas Públicas de Defesa e Segurança na Fronteira Setentrional Amazônica: Reflexões sobre a condição fronteiriça amapaense". Revista Intellector, Vol. XI, no 22, p. 129-147, janeiro/junho, 2015.

TOSTES, José A. "Transformações e dinâmicas urbanas ocorridas nas cidades do Estado do Amapá no período de 1950 a 2010". In: PORTO, Jadson L. R.; NASCIMENTO, Durbens M. (Orgs.). Dinâmicas periférico-estratégicas da fronteira da Amazônia Setentrional: das políticas públicas e redes institucionais à integração espacial. Rio de Janeiro: Publit, 2013. P. 63-92.

Transformações urbanas das pequenas cidades amazônicas (AP) na faixa de fronteira setentrional. Rio de Janeiro: Publit, 2011. 
"Do Norte ao Sul do Estado do Amapá: A Configuração Urbana de Quatro Pequenas Cidades.". In: TRINDADE JR, Saint Clair et al (Org.). Pequenas e Médias Cidades na Amazônia. 1ed. Belém: ICSA -UFPA, 2009, v. 1, p. 219-242.

WESLEY, Maria H. A. "Fronteiras transnacionais, territórios cibernéticos e os impactos na cultura e na soberania nacional". In: SEMINÁRIO SOBERANIA NACIONAL E RELAÇÕES INTERNACIONAIS, Rio de Janeiro. Promovido pela ABD em 22/10/211, 2012. 